Lodz Papers in Pragmatics 14.1 (2018): 45-68

Special issue on Narrating hostility, challenging hostile narratives

https://doi.org/10.1515/lpp-2018-0003

\author{
Majid KhosraviNik \\ Newcastle University \\ Eleonora Esposito \\ University of Navarra
}

\title{
ONLINE HATE, DIGITAL DISCOURSE AND CRITIQUE: EXPLORING DIGITALLY-MEDIATED DISCURSIVE PRACTICES OF GENDER-BASED HOSTILITY
}

\begin{abstract}
The communicative affordances of the participatory web have opened up new and multifarious channels for the proliferation of hate. In particular, women navigating the cybersphere seem to be the target of a disproportionate amount of hostility. This paper explores the contexts, approaches and conceptual synergies around research on online misogyny within the new communicative paradigm of social media communication (KhosraviNik 2017a: 582). The paper builds on the core principle that online misogyny is demonstrably and inherently a discourse; therefore, the field is envisaged at the intersection of digital media scholarship, discourse theorization and critical feminist explications. As an ever-burgeoning phenomenon, online hate has been approached from a range of disciplinary perspectives but has only been partially mapped at the interface of meaning making contents/processes and new mediation technologies. The paper aims to advance the state of the art by investigating online hate in general, and misogyny in particular, from the vantage point of Social Media Critical Discourse Studies (SM-CDS); an emerging model of theorization and operationalization of research combining tenets from Critical Discourse Studies with scholarship in digital media and technology research (KhosraviNik 2014, 2017a, 2018). Our SM-CDS approach to online misogyny demarcates itself from insinuation whereby the phenomenon is reduced to digital communicative affordances per se and argues in favor of a double critical contextualization of research findings at both digital participatory as well as social and cultural levels.
\end{abstract}

\section{Keywords}

digital discourse, online misogyny, digital hate, Critical Discourse Studies, Social Media CDS 


\section{Hating in the cyber sphere: New affordances and practices}

The fast-emerging technologies of the participatory web have brought about an authentic socio-communicative revolution that has transformed the way we communicate, explore and connect to the world forever. "Constant connectivity", the immediate and on-going access to global news, interests, contacts and different modes of expressions, has become a taken for granted part of life in most Western societies (Keipi et al. 2017: 2). Social media, as a paradigm of communication (rather than the platforms or digital interfaces themselves) and as a central notion in digital participatory revolution, has not only provided digital counterparts for all forms and genres of daily offline communications, but has also created a range of indigenous genres and communicative contents and practices.

Social media communication paradigm is characterized by the communicative affordance that digital interfaces provide, at the intersection of mass and interpersonal communication (KhosraviNik 2017a). As such, a social media communicative practice and space pertains to any "electronically mediated communication across any electronic platforms, spaces, sites, and technologies in which users can: (a.) work together in producing and compiling content; (b.) perform interpersonal communication and mass communication simultaneously or separately - sometimes mass performance of interpersonal communication and; (c.) have access to see and respond to institutionally (e.g. newspaper articles) and user-generated content/texts" (KhosraviNik 2017a: 582). Within such qualifying conditions, a wide range of digital forms and spaces would be deemed as social media communication, including the obvious Social Networking Sites (SNSs) e.g. Instagram and Facebook, Micro/blogging sites such as Twitter and tumblr, content aggregators such as Wikipedia, link-sharing sites such as Digg, various discussion forums and Instant Messaging Apps with the possibility of creating group communication such as WhatsApp and Telegram.

In contrast to restrictions on time and place in offline social communications, the social media communication in the cyberspace affords an always-on availability for such practices, allowing for constant pursue of personal interests in a shared scenario as well as for the creation and maintenance of global relations that validate and support identities and behaviors (Allen, Szwedo and Mikami 2012; Davidson and Martelozzo 2013). As an interactive, pluri-directional and multimodal realm, the cybersphere is also characterized by the incessant production and sharing of information content, with an ever-growing number of bottom-up discourse formations and disseminations. Social media "technologies have broken the uni-directionality of content flow from producers to consumers via (gated) mass media practices; and, at least on the face of it, have empowered ordinary users by having the option to participate in text production and distribution" (KhosraviNik 2014: 291). Social media communicative space is characterized by a constant potential for ordinary (rather than élite) media performance (and its relative consequences in terms of mass contribution, engagement and impact), contributing to the gestation of a modern cyberculture. 
One of the most significant and complex drawbacks of the proliferation of usergenerated content, and the so-called democratization of access to symbolic recourses, is the acutely increasing incidence of online hate or cyberhate. The very global, immediate and participatory nature of social media communication paradigm has made the cybersphere a breeding ground for the expression and dissemination of a range of exclusionary, intolerant, and extremist discourses, practices and beliefs (Kopytowska 2017). Cyberhate is generally defined as any digital act of "violence, hostility, and intimidation, directed towards people because of their identity or 'perceived' difference" (Chakraborti et al. 2014: 6). In a broader sense it is viewed as "any use of electronic communications technology to spread antiSemitic, racist, bigoted, extremist or terrorist messages or information"1 (Anti-Defamation League 2010: 4).

In other words, within a widely unregulated, free cyber sphere, the Internet has become "the new frontier for spreading hate" (Banks 2010: 234). One of the key scholarly assumptions on how and why such electronic discourses are on the rise is that social media affordances act as a force multiplier, both in terms of sheer quantity and vitriolic quality of interactions. Some of these digital features and communicative affordances have been specifically flagged by scholars in Social Psychology, Criminology, as well as Media and Communication Studies, as playing crucial functions in the unique spread, consolidation and salience of digital discourses of hate.

Anonymity, or in actual fact, perceived anonymity, is one of the most widely recognized factors boosting online hostility. It is regarded to play a major role in freeing people from following social norms and conventions as they do not feel the threat of a sanction or accountability for their acts (Wallace 2016). The assumption of anonymity results in disinhibition, i.e. the "apparent reduction in concern for self-presentation and the judgement of others" (Johnson 1998: 44 cited in Thurlow et al. 2009: 62). The disinhibited behavior is also referred to as the Gyges effect (Hardaker 2013), in reference to Plato's myth of the Ring of Gyges. The myth tells the story of a man with a magical ring, which brings him the power of invisibility; being invisible, he commits a number of immoral acts to seize the throne of Lydia. The Gyges effect has come to indicate the role of online anonymity and its social repercussions, e.g. the disinhibition of users online in unleashing unrestrained (and harmful) interactions on social media spaces that would not be replicated in face-to-face contact. The notion of anonymity is here viewed loosely, on a spectrum ranging from absolute anonymity to a perception of it, merely as communication on virtual spaces. Anonymity online is related to the assumption that cyberspaces are intrinsically different from real interactions, i.e. less important, freer and differently valued. This is one of the main reasons why an overall feeling of anonymity influences how people act online (Joinson 2003), despite the fact that they often reveal their names, pictures, and affiliations when joining social networks, creating video blogs, or sending e-mails (McKenna and Bargh 2003). Part of this perception is due to physical separation, which is also regarded

\footnotetext{
${ }^{1}$ The absence of gender in this definition is very relevant to this study and will be discussed in Section 3 .
} 
as a factor for the exacerbation of incivility and violent behavior online (LewandowskaTomaszczyk 2017). On the one hand, the lack of a face-to face context, and the related acknowledgement of each other's humanity, may play a role in the increase of aggressive impulses online (Weisband and Atwater 1999). On the other hand, the lack of non-verbal cues (e.g. facial expressions, body language, etc.) in online communication (AmichaiHamburger and McKenna 2006) has been linked to an overall augmented perception and impact of online aggression, as the message salience is entirely concentrated in the text (Guadagno and Cialdini 2002; Epley and Kruger 2005).

Closely linked to anonymity is an overall sense of de-individuation in the cybersphere, i.e. "a subjugation of the individual to the group and a concomitant reduction in self-focus" (Thurlow et al. 2009: 63). De-individuation, therefore, reduces self-awareness and fosters a sense of we-ness and group identity even by means of "weak ties" (Granovetter 1973; Baider and Constantinou 2014).), such as a single shared interest or hobby. Millions of people can be reached through an "inexpensive and unencumbered social network that has enabled previously diverse and fragmented groups to connect, engendering a collective identity and sense of community" (Banks 2010: 234). Related to the depersonalizing effect of online de-individuation are group salience and polarization. Online communication can foster the acceptance of group norms over individual standards of behavior (Postmes et al. 2002). This loss of individuality is deeply linked to the loss of personal responsibility and allows for the formation of "cyber mobs" (Citron 2009) and the spread of mob dynamics and mob mentality online, often resulting in an ever-escalating competition to attack people online because of their perceived difference. The aforementioned dynamics of deindividuation and group salience often result in the absence of contradicting or moderating voices, paralleled by an exaggeration and polarization of common divergences between opinions, visions and segments of society (Wallace 2016).

Such digital characterization, together with psychological explorations on the mechanism of cyberhate, constitutes the theoretical and technological context of the manner, range and extent of these discursive practices. The recognition of strong psychological features in antisocial behaviors like hate speech is basically entrenched in the differences between face-to-face communication and online interactions. However, it is important to note that humans have always been interacting with each other and appropriating mediation technologies in their social communication. While it is reasonable to say that the digital affordances and specifications may have a lot to do with the range and quality of certain norm of communication, nevertheless, the construction, perception and communication of hate is primarily a social construct, i.e. constituted in the socio-cultural, socio-political and socio-economic context of the society. The social context, or, in Couldry's (2012) terms, the "thick context" is the forbearer of what is referred to as the network of discourses-in-place which constitutes the culture and social perspective on the backdrop of a diachronic build-up of knowledge/stance accumulation (KhosraviNik 2015a; 2015b). 
As such, an analysis of a digital communicative phenomenon such as discourses of hate is contingent upon the two levels of horizontal (industrial) contextualization on top of a vertical (social) contextualization (KhosraviNik 2017a). On the horizontal level, the specific communicative affordances and possible repercussions are accounted for, while in the vertical level the discursive practices are positioned and explicated within the cultural and social norms (or big D discourses) and Foucauldian networks of knowledge in society. Any social media communicative phenomenon is shaped and scaffolded both by the digital and social contexts. Such an approach would deliberately steer away from media determinist accounts as well as from universalist understandings of social media effect (KhosraviNik and Kelsey, forthcoming). Similarly, it would prevent any dilution and trivialisation of online hate as a normal feature of the Internet, considered as a selfregulated, independent realm. Communication is to be seen as a human endeavor, regardless of the sophistication of the medium used. Therefore, its critical investigation will focus on the human as member of a specific social construct, not merely on the technology of mediation.

\section{Online hate as communication and practice: Beyond flaming and trolling}

We have seen how the interactive and intertextual nature of the cyberspace allows groups and individuals with similar (often radical) ideas to connect and express explicit manifestations of hate, which, supported and further inflamed by other Internet users, often result in the emergence of a "discursive spiral of hate" (Kopytowska et al. 2017: 68). The international debate on the viral nature of online harassment has largely been envisaged around the notions of trolling and flaming, too often employed as umbrella terms for several and extremely different negative online behaviors related to uninhibited online communication.

In early definitions, flaming has been regarded as a general expression of "strong and inflammatory opinions" (Siegel et al. 1986: 161) as well as "expressing oneself more strongly on the computer than one would in other communication settings" (Kiesler et al. 1984: 1130). However, these general definitions do not seem to fully account for the "aggressive, hostile, profanity-laced" nature of the phenomenon (O'Sullivan and Flanagin 2003: 70). In fact, flaming is usually characterized by "profanity, insults, negative affect, and 'typographic energy' such as capital letters and exclamation marks" (Jane 2015: 66; see also Lea et al. 1992), and entails "swearing or using otherwise offensive language" (Moor et al. 2010: 1536). In a broader perspective, flaming can be seen as a natural part of the techno-discursive design of social media and the shift in digital communication prioritizing affective expressionism over rational resonance (KhosraviNik 2018).

Trolling is another recurrent catch-all term to describe everything from "playground insults, sick jokes, and deliberate insensitivity right through to threats of violence, rape and 
murder" (Hardaker 2013). What seems to characterize trolling is the deliberate act of luring others into useless circular discussion, with the result of interfering with the positive and useful exchange of ideas in a given environment (such as an online forum), shifting the dialogue into a confusing, unsuccessful and unproductive exchange (Herring et al. 2002: 372). This is often achieved by posting meaningless and incendiary comments with the exclusive goal of fueling an equally aggressive reaction, enjoying the resulting disharmony and conflict (Fichman and Sanfilippo 2016).

Despite the widespread (and often overlapping) use of these two terms, the utmost complexity of the discursive practices and behaviors of online hostility has somehow managed to hinder the development of principled definitions and univocal terminology. Far from being a trivial aspect, terminology is part and parcel of the conceptual, methodological, and epistemological challenge posed by cyberhating. In fact, the early concerns with the issue of digital hostility have arisen since the very initial development of forums and chatrooms, as the early versions of social media communicative spaces. However, in the "first wave" of studies on online hostility (Jane 2015; see also Jane 2017), throughout the late 1980s and 1990s, scholarly research got quickly stuck in a polarized debate on the actual nature of Computer Mediated Communication (henceforth, CMC). On the one side framed as a "rational, efficient and productive" way of communication, CMC was also quickly labelled as "irrational, deficient and disruptive" due to the proliferation of "uninhibited behaviour" (Lea et al. 1992: 91). This resulted also in a polarized, sterile conceptualization of flaming, mainly either foregrounding the role of society over technology or vice versa in the origin of the phenomenon (Jane 2015: 67).

The "second wave" (Jane 2015: 68) of research on flaming employed complex working definitions and theoretical models aimed at classifying user-generated content (see Turnage 2007; Kaufer 2000). Grounded in a more balanced attention for both message content and context, O'Sullivan and Flanagin's (2003) approach aimed at developing "precise conceptual and operational definitions" (p. 69) and a system for the identification of "true flames" (p. 82) in forums and emails. However, their application to the more recent digital interfaces proves to be practically, epistemically and conceptually difficult (Jane 2015:70), complicated by the evolving Web communication and its growing intricacy and virality. In the meantime, the super connectivity, integration and divergence of digital practices, outlets and devices also enhances the impact of digital cyberhate, turning it into a socially relevant discursive practice rather than an isolated online dynamic.

Within a saturated context of social media spaces and their unprecedented diversity and intensity of use, the "third wave" (Jane 2015: 69) of research has questioned the available theories, methods and terminologies related to online hate. Topics like flaming and trolling are absent in the most recent handbooks on Internet Studies (Hunsinger et al. 2010; Consalvo and Ess 2011; Dutton 2013), however according to Jane (2015: 69) this has too often resulted in scholars overlooking the phenomenon for the simple fact that they were not able to grasp it in its complex entirety. Third wave scholars like Lange (2006) have claimed that the term flaming is "exhaustively oversaturated" and the solution to the debate 
would lie "not with finding a more precise definition for flaming" but with "extinguishing the term 'flaming' itself'. At the face of the impossibility of developing a systematic and infallible methodology for the definition and identification of what constitutes (or does not constitute) a "true flame" (O’Sullivan and Flanagin 2003: 82), a more ethnographic, less taxonomic approach to online hostility would potentially represent a more useful and relevant insight into how participants in CMC "maintain, challenge and negotiate" cultural norms which are "constantly in flux and potentially at odds", both "into and out of existence" (Lange 2006).

Some considerations are to be taken on-board in the development of a critical research to online hostility as a "full-blown set of cultural norms and set of linguistic practices" (Coleman 2002: 109). To start with, Lange's (2006) call for academics to avoid "engaging in a moral categorization that takes sides" may easily risk derailing in "a moral relativism and scholarly detachment" (Jane 2012: 539), which ignores the tangible social impact of online hate and may result in an underestimation and trivialization of the phenomenon. A crucial point here, probably a lesson to be learned from the three waves of studies on online hostility, is not to dilute a socially relevant and serious phenomenon into a cybernetic (playful?) game/dynamic. Too often a recreational undertone in flaming and trolling-related literature has hindered framing the issue within a narrative of criminal aggression having a social, material and ethical relevance. Similarly, it has hindered the acknowledgement of online hostility as an actual strategy to silence and exercise control over disadvantaged groups who may benefit from the participatory potential of the cyber sphere more, especially those who have historically challenged the unequal distribution of power within society (i.e. women, see Section 3). According to Sarkeesiaan (2015), assigning a juvenile and goliardic nature to the phenomenon of trolling, reinforced by comments like "don't feed the trolls," "it's just boys being boys," and "it's just the Internet," has contributed to the normalization of online harassment as an integral act of digital citizenship. The definitive abandonment of the terms flaming and trolling in favor of other less saturated and loaded alternatives, such as cyberhate and "hate speech" (Citron and Norton 2011) or "e-bile" (Jane 2014), could be a viable starting point to foster a more mindful approach to the violent and exclusionary nature of online hostility, rather than edulcorating the issue by focusing on its playful and communally participative aspects.

Furthermore, the refusal to acknowledge flaming as a result of "cultural norm violations" (Lange 2006) may make matters worse. On the one hand, it may translate into an exculpatory narrative, framing online hate as a legitimate user "retaliation against a community that they feel has stripped away their identity and alienated them" (Suler and Phillips 1998: 277). On the other hand, it may foster an upfront celebration of flaming as a liberating, anti-hegemonic act of free speech, a "laudable and savvy resistance to mainstream media norms" (Jane 2012: 539, see also Phillips 2011; 2012). On a broader level of analysis, we must acknowledge that the obsession over the methodological framing of the phenomenon, entangled with exhilaration over newly found communicative affordances both on the side of the users and researchers, has too often swayed the academic 
discourse away from the important social, ethical, and political aspects of this phenomenon. Lack of interdisciplinary synergization between media and technology approaches and more established (traditional?) social sciences have contributed to rifts in interpretations at the cost of critical socially relevant research (KhosraviNik 2017a; 2017b) This type of technological preoccupation is a recurring pitfall in analysis of any socially, politically relevant topic, e.g. the digital politics of protesting, representation etc. (KhosraviNik 2017a; 2017b; KhosraviNik and Unger 2016; KhosraviNik and Sarkhoh 2017).

\section{Towards a critical definition of online misogyny}

Although misogynistic violence represents a compelling social problem, both institutional and scholarly research have often dismissed or neglected the recognition of misogyny as a form of gender-based hate speech. The Organization for Security and Co-operation in Europe (OCSE) has defined "hate speech" as the expression of hatred towards an individual or group of individuals on the basis of "protected characteristics", such as "membership to some specific social group that could, on its own, trigger discrimination" (OSCE 2009: 37 46). The taxonomy of these characteristics, and whether these include gender, remain very much open to interpretation (see Kopytowska and Baider 2017: 139). In line with the 2010 definition of the Anti-Defamation League (see Section 1), also the No Hate Speech Movement campaign launched by the Council of Europe in 2013 makes a very clear reference to "nationalism and ethnocentrism, discrimination and hostility against minorities, migrants and people of immigrant origin" as the main sources of hate and discrimination (Council of Europe's Committee of Ministers' Recommendation 97 (20); cf. Weber 2009), essentially leaving out of the equation such characteristics as gender, gender identity and sexual orientation. Entries such as misogyny or sexism also fail to appear in the online glossary of terms developed in the context of the same campaign.

The relative absence of gender from most institutional definitions of hate speech represents a clear sign of a blind spot and epitomizes the institutional failure to acknowledge gender as a social factor that, per se, suffices to trigger hate (see also Titley 2012). Many factors are at play in this respect, as identified by Lillian (2007). To start with, the widespread assumption that gender equality has been substantively achieved, leaving nothing but a residue of sexism in popular culture, may account for the reluctance to discuss sexist speech in terms of hate speech. Another reason for the exclusion of gender as a hate factor is that while hate speech targets "members of vulnerable minorities" (Waldron 2012: 5 ) with racial and xenophobic aggressions aimed at their complete elimination from a given community, the same cannot be argued for women (Lillian 2007). These assumptions, however, fail to account for the numerous ways in which women are targeted by sexist and sexually violent speech and denigrated within moralizing, patriarchal frameworks in what can be regarded as one of the "most complex and pervasive system[s] of oppression" (Lazar 2007: 143). 
Feminist scholarship, on the one hand, has framed online (and offline) misogyny as strategies for perpetuation of patriarchal social hierarchy and, on the other hand, has substantiated a direct link between online harassment and the gendered nature of digital contexts (see Jane 2016; 2017). A critical approach to online misogyny draws on feminist studies for a full and systematic acknowledgement of misogyny as a form of hate speech. In so doing, it further problematizes the social and cultural mechanisms of misogyny and the role of gender-based harmful speech in gendered social orders. While a discussion of the vast array of feminist theories on the issue is beyond the scope of this paper, two aspects require particular attention in a critical outlook to online misogyny.

Firstly, the acknowledgement of women's precarity in the cybersphere, as generated by the adherence of its users to gendered social norms (Butler 2009). Starting from the assumption that conformity to these social norms creates a "differential allocation of recognizability" (2009: ii), and any violation attempt entails becoming "differently exposed to injury [and] violence" (2009: ii), women, unlike men, are to be regarded as inhabiting the cybersphere as precarious subjects. Being less recognizable and, therefore, less powerful, their active participation in the online public sphere may easily translate into a non-compliance with the social norms of gender ideology, and trigger harmful, sexualized speech to restore the order.

Secondly, an awareness that the subordination of women as precarious subjects in the cybersphere is largely achieved and maintained by means of harmful speech acts (Langton 2012: 80) with a precise illocutionary and perlocutionary force aimed at annihilating certain groups, legitimating their discrimination, advocating violence and hatred and producing changes in attitudes and behaviors. Not only targeted by an exceptional amount of hostility, women's voice online is also silenced by the very asymmetry in the ability to perform certain illocutionary acts, as measure of authority and power (Langton 1993). Moreover, the affordances of the participatory web promote an exponential augmentation of the illocutionary and perlocutionary dimensions of online misogyny, performed within a "collapsed context model" (Marwick and Boyd 2014) which is potentially boundless, and hence enhances exponentially the effect on behaviors and beliefs of a limitless number of people.

\section{Social media discourse and critique}

The disciplinary boundaries between social sciences and media and technology scholarship partly stem from epistemological distinctions informing the fields as well as from the perceived incompatibilities of a viable merger. This is the same lack of interdisciplinarity, which, on the one hand, could hinder flaming-related studies from making meaningful critical social contextualization of the issue and on the other hand, could outdate discourse theory in engaging with digital media contexts. This is because the interactive affordances provided by the social media communicative paradigm have posed serious challenges to the bulk of theories in mass media communications, e.g. around the notion of discursive 
power and the way audiences have been defined within decades of theorization (KhosraviNik 2014). The traditional gatekept, unidirectional, one-to-many interface of mass media is now replaced with what appears to be a (potential for) many-to-many dynamic of discursive practice hence mass media's grand discourse and their concentrated power to push content onto audience is replaced by new forms of participatory communication. This could be viewed as a form of de-monopolization of access to discursive power in social media. The notion of power behind discourse, i.e. established discourses-in-place in society in Foucauldian sense, has always been the center of theorizing the role of semiotic resources in society. This explains the traditional preoccupation of Critical Discourse Studies (CDS) (Wodak and Meyer 2016; Fairclough 2003) with mass media as an obvious powerful site where discursive power is exploited to (re)construct and (re)define social realities. From CDS vantage point, culture is nothing but a network of (more or less resident) discourses-in-place in a given society within a synchronic and diachronic architecture (see KhosraviNik 2015a; 2015b). As such, collective identities including gender related constructs are inherently envisaged through discursive processes where boundaries of difference, uniqueness, and distinctiveness are constituted/marked/represented.

In line with the increasing and multifaceted use of social media model of communication as new cultural forces of identity performances, the participatory web provides exciting new opportunities for studies on various collective representations (KhosraviNik and Sarkhoh 2017). In Susan Herring's (2001: 625) words, "the discursive negotiation and expression of social relations in cyberspace including asymmetrical relations, constitutes to be one of the most promising areas of future investigation". As "a socially committed, problem-oriented, textually based, critical analysis of discourse (manifested in communicative content/practices)" (KhosraviNik 2017a: 586), CDS is bound to include and account for recent shifts in the concentration of discursive practices on digitally facilitated spaces, i.e. there is discursive power where there is communication concentration.

Yet, CDS is indispensably in need of making substantial new interdisciplinary synergies with social media theory and scholarship (KhosraviNik and Unger 2016) to be able to account for new techno-discursive architecture of new media (KhosraviNik 2018). It is important to note that, as necessarily as the new transdisciplinary engagements are, such an endeavor "should not (a.) cause an epistemological overhaul for social orientation of CDS, e.g., shades of media determinism and dilution of critique and (b.) force CDS into substantial tired defensive debates on old issues, e.g., why the descriptive level of analysis needs a critical explication" (KhosraviNik 2017a: 586). A critical digital discourse analysis of identity construct maintains a strong connection with social theory although it has to incorporate a significant interdisciplinary knowledge and conceptualization around nuances of digital practices and techno-discursive intricacies of cyberspace discursive practices (KhosraviNik 2018). Such a social media approach to CDS (SM-CDS) would 
then fill crucial gaps in scholarship on socially relevant but digitally mediated discourses, e.g. digital misogyny discourses.

Another crucial caveat is to guard against digital determinism (KhosraviNik and Kelsey forthcoming). Just because every individual can (apparently) perform his or her own identity online, it does not mean that the society as a structure is not relevant anymore. Neutralizing (problematic) social structures and histories by drawing on (arguable) digital access to representations is undoubtedly reducing life worlds in unproductive ways and vice versa (KhosraviNik 2017a). In line with issues such as digital divide (Ragnedda and Muschert 2013), and despite difficulties in demographic and geographic accounting of online communities, macro-contextual qualities of a given society including materialities of class, ethnicity, gender, agency, cultural capitals, as well as cultural positioning, stereotypes, power structures, histories etc. should not be "distilled into a bland cybernetic metaphor" (Couldry 2012: 117).

Social Media Critical Discourse Studies approach (SM-CDS) deals with discourse as its central object of analysis - not the technology, i.e. it is not only interested in what happens in the media per se as a closed loop but also in how it may shape and influence the social and political sphere of our life worlds and vice versa (KhosraviNik 2014; 2017a). In other words, the media specific (horizontal) context of participatory web should not be taken as an equivalent of the vertical social context. As such, digital performances of identity, conflict, and misogyny are to be interpreted within a wider socio-political context, which embeds the digital mediation. The guiding bottom line here is that meanings are negotiated at the intersection of individuals, culture, and media technology (KhosraviNik 2017b, see also Kopytowska 2013, 2015; Kopytowska and Chilton, this Special Issue). At the intersection of resident cultural norms, technological affordance and the given individual, digital critical discourse studies would be interested in both micro communicative patterns as well as the macro-discursive regimes which constitute the culture.

\section{For a critical analysis of misogyny discourse online: The Janus Effect}

Hostility is a complex social, cultural and psychological phenomenon, whose utmost multifacetedness has been amplified by the new affordances of the participatory web. Motives behind people's hate are various, different and often obscure, and the very fluid nature of the cybersphere adds to further complicate an already thorny matter. Digital multivocality and virality contribute to guarantee cyberhate a potentially infinite resonance, both online and offline. At the same time, gender has not received sufficient institutional and academic attention as a source of hate in its own right. While the dangers and risks of the digital world are well acknowledged, we still lack a clear grasp of what it actually entails being a woman navigating the cyberspace, and which specific threats and troubles this journey can bring about. 
As we approach online misogyny from a critical perspective, we are faced with too many epistemic battlefronts, a phenomenon that we refer to, metaphorically, as the Janus effect. The Roman god of beginnings and ends was, in fact, at an advantage compared to us: he only had two directions to look at, forwards and backwards. As we tackle misogyny in the cybersphere, we are compelled to look in different, and intricate directions, none of which can be regarded any more or less important or urgent. This is in line with the breakdown in the linearity of textual flow and foci of production and consumption of meaning making artefacts. The dynamic of one-to-many communication, which has been the hallmark of textual practice in mass media and elite discourses, is now changed into a potential for many-to-many dynamic of textual practices by countless number of ordinary prosumers in a fluid, circular and unpredictable manner (KhosraviNik 2014). In essence, the opportunities for identity performance are endless and extremely individualized (KhosraviNik 2018), but so are the dynamic of power for harassment, hate and misogyny. As it is the case for classic CDS approach, theoretical and methodological aspects of research are intertwined in the technological fabrics of the media(tion) under investigation. While in the case of mass media the discursive power has been identifiably concentrated in the hands of media elites (owners, editors, gatekeepers), the new social media communicative spaces (seem to) afford an individuated potential for expression of identity, conflict and affects with little or no direct accountability. Despite the ontological changes in the media landscape, which automatically calls in new epistemologies for research, the media technology is not to be taken as the definitive formidable force for shaping the processes of discourse formation and perception. That is, misogyny, like other discriminatory practices, is rooted in social conditions, constructions and genealogies of knowledge structures (Foucault 1971). Nevertheless, the technological changes at the intersection of discourse and society, i.e. digital media(tion) industries, play a crucial role in the scale, characteristics and mechanism of new digital discursive practices of symbolic violence, discrimination and hate.

In this section, we sketch what we believe are some of the main aspects to take into account when approaching online hostility, around two main themes to be discussed below: interdisciplinarity and empirical text-based approach. Only by putting all these considerations together, in the context of contemporary participatory web, we could attempt at highlighting the demarcations, assumptions and identities around online misogyny discourses in new media ecologies.

\subsection{Interdisciplinarity}

As a general key argument, we believe that audacious, substantial, invasive interdisciplinarity is the sole way forward to make fresh contributions both for the fastdeveloping scholarship in Social Media Discourse Studies as well as for studies on digital misogyny, hate and harassments. Much of the useful theorizations of the analysis of language on social media or CMC have been produced by scholars who are firmly positioned either within a sociolinguistic frame (Androutsopoulos 2008) or (rather 
descriptive) discourse analysis (Herring 2004). Both these approaches, in fact, have taken important steps in accounting for new digital dynamic of communication by arguing for adaptations to established practices in the field in terms of methodological approaches and genre specific features of the data online. A Social Media CDS approach to misogyny would build on these contributions, i.e. to account for the horizontal digital media context elaborated by digital ethnographic proposal of Androutsopoulos (2008) and dealing with pragmatics of meaning making and discourse analysis of digitally tailored communication genres of Herring (2004). At the same time, SM-CDS theory and method borders a range of influential approaches and debates in the wider field of social media theories and digital communication. In addition to the micro issues of data analysis and incorporation of observational ethos, there is a major synergic critique that SM-CDS identifies with, i.e. the integration of analysis of discursive practice online with the social contexts.

Moreover, applying a SM-CDS to the study of online hate against women also means keeping strong references to Gender Studies and Feminist Critique. In approaching online misogyny, we would always start from the assumption that any online form of gendered violence replicates and extends the gender and power relations that pre-exist digital communications technologies and vice versa. In other words, the assumption that discourse, regardless of the its technology of media(tization), is constitutive as well as constituting the society (Fairclough and Wodak 1997). As a form of digital discourse targeting women on the specific basis of their gender, misogynistic speech would be deemed as a purposeful discursive strategy to maintain a gendered asymmetry of power by threatening, discrediting and ultimately silencing women in a way that it has historically been regimented ${ }^{2}$. When translated in the cybersphere, gender-based discrimination becomes a new, subliminal form of digital divide, having the potential to reduce the equality and inclusivity of both on- and off-line cultures. Only a feminist social critique of online misogyny would allow and be capable of accounting for gender-based inequality, bias and stereotyping in institutional, public and media discourses as the humus of online misogyny.

Critique per se can be regarded as an interdisciplinary effort. An integrated critical approach is needed to highlight the existing links between the new online discursive practices and the socio-political context of the offline world and its established power relations. The CDS notion of critique allows us to consider the wider socio-political conditions, which shape discourse and making visible the "interconnectedness of things" (Fairclough 1995: 747). The systematic analysis of discourse reveals structures of power and unmasks ideologies (socio-diagnostic critique), with the ultimate aim of contributing towards the betterment of society (prognostic critique) (Reisigl and Wodak 2001). Starting from the analysis of discourse-internal structures and strategies (and a relative, discourseimmanent, critique) entails a strongly text-based approach, to be discussed below.

\footnotetext{
${ }^{2}$ See Baider (this Special Issue) who draws the same conclusion related to the reinforcement of the asymmetry of power in her study focused on homophobic discourse.
} 


\subsection{Empirical text-based approach}

Both social psychologists and criminologists, authors of the bulk of studies on online hate, have attempted at sketching haters' underlying motivations and strategies by drawing on psychological theories and research. As we have seen, these studies have provided good insights into disinhibited online behavior, highlighting how some features inherent to CMC (e.g. perceived anonymity and physical separation) contribute to trigger social practices online (e.g. de-individuation, polarization, mob dynamics). One of the dangers of relying on these scholarly interpretations is the relatively straightforward establishment of a causeeffect relation between the affordances of the participatory web and practices of hostility online, highlighting the role of the medium and downplaying socio-political structures and power hierarchies.

One major, taken-for-granted assumption is that misogyny is demonstrably and inherently a discourse. On the conceptual level, this means that it is a social phenomenon scaffolded by collective communication and processes of representation and knowledge formation. In other words, it has antecedents and consequences. It also means that there is a level of social power at work, which can contribute to the normalization of unequal social structures and norms. Therefore, the very assumption that online misogyny is a discourse enforces the requirement of critique, engagement and contextualization. On the methodological level, this assumption indicates that the study follows a combination of inductive empirical observation, analysis and interpretation based on concrete set of communicative content (or texts, to use classic CDA terminology), as well as being deductive when it comes to explicating the findings of the textual analysis within the wider social theory ${ }^{3}$. This would then serve a double purpose for the approach. Firstly, in contrasts to speculative approaches, a SM-CDS study of online misogyny engages with various levels of data (including various forms of meaning making and practices as well as a variety of semiotic resources), i.e. the study would have details of communicative patterns and meaning makings as they occur. Secondly, it affords a requirement of critical engagement and social theorization for the study, i.e. power relations are discursive hence a study as such needs to integrate critical social theory. In essence, the assumption that misogyny is a discourse equips the approach with both methodological rigor at the micro analytical level and emancipatory mission at the macro societal level. In the meantime, it guards against the media deterministic understanding of gender based online harassments as a collective feature of digital technologies of mediation. If "hate speech seeks to move an audience by creating a symbolic code for violence" (Whillock 1995: 32), then only a text-based analysis can capture the complex nuances of the code itself. Similarly, the approach maintains that misogyny is foremost a communicative event rather than a neutral digital event, i.e. it is nurtured by the materiality of life worlds and lived experiences of online prosumers as

\footnotetext{
${ }^{3}$ Within a SM-CDS approach, the term text is replaced by communicative content and practices to capture the dynamic nature of meaning making in social media communication (see KhosraviNik 2017a; KhosraviNik and Kelsey, forthcoming).
} 
communicative via the new digital affordances. As a communicative event, the analysis of discursive practices of misogyny online is about engagement with styles, the relevancies, the horizontal and vertical context intertextualities, patterns, etc. of the communication itself.

At the same time, the SM-CDS approach to online misogyny is also acutely aware of the specificities of the digital dynamic of communication. The critical demarcation against media determinism in no way entails a downplay of the intricacies of the digital technologies and the ways they may promote certain styles of communication. In fact, as part of its feature interdisciplinary approach, SM-CDS has explored issues around political economy of social media, the function of algorithmic regimentation of content, corporate valorization of interaction online and affective stylization of communication on social media spaces (KhosraviNik 2017b; 2018; KhosraviNik and Kelsey forthcoming). To be able to capture the ethos of interactivity, connectivity and always-on nature of social media communication (Hine 2000), one major trajectory is to adopt immersive, digital ethnographic/observational approaches in SM-CDS. This would allow the approach to account for communicative intricacies on the digital ground, with the ideal aim of capturing the various psychological, communicative, technological and affective dynamics around digital misogyny. The main caveat, and indeed a major challenge, is to maintain a healthy balance between theory and practice, between speculation and inductive analysis and, most importantly, between the social theory of discourse and new ontologies of dataism and extreme individualization. Studying social media means dealing with new time, new technology, new industry, new discursive power, new affordance, new genres and new practices, so major interdisciplinary leaps would have to be made by drawing on new research domains in digital technologies. However, it is still the society, its discursive structures, cultural contexts, genealogies of knowledges, discourses-in-place and issues around discrimination and inequalities to represent the core object of study. Accounting for communicative structures and norms of new media technologies should not result in reducing the notion of society into a cybernetic space (KhosraviNik 2014; 2017a).

Logistical issues around selection and sampling of cases and areas of relevant discursive concentrations are among the meso-level operationalization considerations. Specifically speaking, the selection of case studies for analyses of online misogyny can be potentially guided by the many various taxonomies of online hostility available in literature. These include gender-specific one, such as the typology recently outlined by Powell and Henry (2017), to include instantiations of: a) gender-based hate speech; b) rape threats; c) image-based harassment; d) sexual solicitation. Other types of online hate are not necessarily gender-specific (such as cyberstalking, cyberbullying, impersonation and doxxing), but they often see women as victims and should be taken into account as different, and more devious, forms of "Technology-Facilitated Sexual Violence" (Henry and Powell 2018). However, these categorizations would not necessarily restrict the focus of the analysis but may only work as general references to support the researcher navigate 
through considerable amount of data and help them to recognize the recurring patterns that contribute to the viral impact of the phenomenon.

As the cybersphere represents an infinite set of data, the adoption of specific social media research software for collection, analysis and visualization of digital data can offer a valid data and method triangulation to the study. An important interdisciplinary overhaul would also entail incorporating the increasing range of emerging methods in social media studies such as big data, data visualization, data mining software, network analysis etc. as well as various adaptations of situated communication analysis, linguistic and multimodal analyses. Software choice depends largely on the focus of the analysis, as well as on the available scale and scope of the projects as they would normally require additional funding. The software will be able to collect data or will operate on datasets, performing few specific analyses (e.g. content, context, co-link, snowball, inter-actor, network, sentiment analyses). While some software is designed for multi-platform analyses, others are most specific in their concentration of operations and design e.g. tweepy for Twitter and netvizz for Facebook. Most available software has been developed for business and marketing needs, nevertheless, they could function as important tools and have been widely employed in peer-reviewed academic research (e.g. Gephi, NodeXL, Datasift).

Further supporting corpus-based software (e.g. Wordsmith Tools) can allow a preliminary, quantitative text-based analysis as a starting point for identifying patterns (see Baker and Egbert 2016) and could focus on key-keywords (words with higher or lower frequencies), collocations (frequent co-occurrence of words) and semantic prosody (consistent aura of meaning of a given collocate). As customary in CDS, the quantitatively analyzed corpus can be systematically down-sampled for close qualitative, manual and critical analysis. This will allow to map the vast number of discursive strategies (e.g. referential, predicational, argumentative, perspectivization, mitigation, intensification etc.) and rhetorical devices through which online misogyny is realized (Reisigl and Wodak 2001; Reisigl 2014). Four different heuristic levels of context would be taken into account, ranging from: 1) the immediate co-text; 2) the intertextual and interdiscursive relationship between utterances, texts, genres and discourses; 3 ) the extralinguistic social/sociological variables and institutional frames of a specific context of situation; 4) the broader sociopolitical and historical contexts, which the discursive practices are embedded in and related to (see Reisigl and Wodak 2009).

Multimodal discourses of gender-based symbolic violence and discrimination represent an established core in socio-cultural regimentation of gender inequality in society (see, for example, the plethora of research in women and advertising both in the past and present). Multimodal digital channels of online hate in general (and misogyny in particular) are now an indispensable aspect of research on digital misogyny. Specifically, image-based sexual harassment and exploitation is a common strategy of online misogyny, entailing "the creation, distribution, or threat of distribution, of intimate or sexually explicit images of another person without their consent (also known as revenge pornography)" (Henry and Powell 2018: 201). As far as the CDS of social media is concerned, multimodality is now 
at the forefront of discursive practice. In fact, multimodality has always been the core perception of discursive formation and perception for members of society but for a variety of reasons including the roots and disciplinary foundation of early discourse analysis, the (verbal) language has been considered as the core communication modality in (classic) CDA literature. In the meantime, while working within similar theoretical and conceptual understanding, the analysis of other channels of communication including images, music, architecture etc. has traditionally been bundled together as multimodal discourse analysis (Kress and van Leeuwen 2006; Machin and Mayr 2012). The case in point is the fact that all the recent works on language of new media would feel compelled to acknowledge the multimodal aspect of online communication (e.g. Page et al. 2014; Herring 2004). It is also important to note that, given the new-ness of the communication technologies and the creative ways the users of various socio-cultural backgrounds use these discursive interactive spaces, a host of indigenous, innovative, unique forms and mechanism of meaning makings is available on social media which would not easily conform to the traditional definitions for multimodal communication, i.e. mainly focused on images and music. Hence, if the multimodal approach is to be taken as accounting for all channels of communication other than verbal language, then the approach is also facing challenges in terms of describing the new communicative genres beyond the usual modalities of audio and visual channels. The participatory web is constantly affording new communicative resources unique to these spaces e.g. tagging, likes, annotation, sharing, hyperlinks, etc. (KhosraviNik 2017a; KhosraviNik and Zia 2014).

\section{En-route to a SM-CDS of online misogyny}

The domain of online misogyny as a digital discursive practice would be at the intersection of digital media scholarship, discourse theorization and critical feminist explication. In doing CDS on social media, the procedure should take into account the new context of interaction i.e. its norms of practice, its indigenous genres and meaning making resources etc. while maintaining the core principles in doing critical social sciences. Drawing on earlier theoretical contributions and major case study carried out within the domain of Social Media Critical Discourse Studies (KhosraviNik 2014, 2017a; KhosraviNik and Unger 2016; KhosraviNik and Sarkhoh 2017), a tentative overall operational procedure for such study is envisaged.

Firstly, a critical discourse study on digital misogyny would clarify the macro contextual elements around both the use of the media technology as well as the sociocultural context of society. The media technology characterization is about the ways the users are discussed as a member of digital world, i.e. the fabrics of the digital reality users would experience. The socio-cultural characterization is about the ways users are discussed as a member of (real) society. The first level would be delineating social media use and technology in that given society, range, size, power, penetrability, norms of use, infrastructures, etc. with specific focus on gender related information, e.g. gender mark up 
of users in different platforms, the background on possible differences in popularity, quality, purpose, and characteristics of use between males and females etc. The second level is the social and cultural fabrics in relation to the use of social media in society with specific focus on gender issues, e.g. quality of already available public sphere and access to it for men and women, range of emancipatory discourses, impetus for gender equality, issues of overall politics, women in power (gender equality in pay, representation, economy, politics etc.).

After a general context setting, the specific context of the chosen platform, site or any other social media space would be detailed (e.g. online forums, Twitter etc.), along with any specific use and suitability for deliberation on gender issues. The next step would be description of discursive event(s) selected, the rationales, range, relevance, background and significance of the data concentration selected including, if possible, information gained through Big Data methods, Network Analysis, Social Media Analysis etc. as they may fit the purpose.

A major, time consuming and substantial part of SM-CDS is the textual analysis (or a range of communicative content e.g. visual, verbal, memes, etc. and meaning making practices regimes of Likes, Tags, RTs, digital stance making, Mentions, orthographic representations etc.), i.e. the systematic analysis of representational resources and behaviors, categorization of themes, identification of salient representations, arguments, manipulations, visual metaphors etc. This would mean analysis of language and other modalities of meaning making, in addition to indigenous technological semiotic resources/practices. The analysis of the communicative content and practices at this stage could draw on various linguistic, visual, semiotic, multimodal etc. methods within the stipulated overall aims of discourse analysis, i.e. to account for What, How and Why questions (KhosraviNik 2010). In a similar vein, Kopytowska (2013) illustrates how the Media Proximization Approach can be applied to computer-mediated communication.

The research enters the analysis of case study communicative content and practices via accounting for the context of technology and society first. Similarly, the findings of the detailed analysis of the communicative content are gradually positioned, examined and extrapolated within the immediate and wider contextual levels. That is, the analysis firstly examines the connection between the new findings with other similar research on digitally mediated communicative content, and secondly explicates the findings within the wider social context on the topic, i.e. scholarship on misogyny discourses in society, mass media, workplace, politics, business etc.

The conclusions of such research would consider findings from micro aspects of the analysis spiraling out to immediate and wider context levels. This would include the emerging trends arising from the data analyzed and the specific features, qualities and themes analyzed; the social media spaces, the network and connectivity afforded by the digital technology, the application of the new affordances, the functionality of the platform(s) etc. Relevant levels of concluding extrapolations would entail the wider discussions on impacts of social media communication around hate speech and misogyny 
discourses in society including explication of new trends, changes, complications around the issue, degrees of intensification or alleviation and possible new ways of discourse formation and communication and perceptions on social media space. The empirical, bottom-up, observed impacts of new affordances of social media technologies, i.e. new dynamics of discursive power for all, potential of many-to-many communication, (the claim to) democratization of access, abolishment of gate-keeping etc. would constitute the valuable overall reflections.

\section{References}

Allen, Joseph, David Szwedo \& Amori Mikami. 2012. Social networking site use predicts changes in young adults' psychological adjustment. Journal of Research on Adolescence 22. 453-466.

Amichai, Hamburger, Yair \& Katelyn Y.A. McKenna. 2006. The Contact Hypothesis Reconsidered: Interacting via the Internet. Journal of Computer Mediated Communication 11. 825-843.

Androutsopoulos, Jannis. 2008. Potentials and limitations of discourse-centred online ethnography. Language@Internet 5(8).

Anti-Defamation, League. 2010. Responding to cyberhate: Toolkit for action. Retrieved from: http://www.adl.org/sites/default/files/documents/assets/pdf/ combating-hate/ADL-Responding-to-Cyberhate-Toolkit.pdf (accessed 12/4/2018).

Baider, Fabienne. 2018. "Go to hell fucking faggots, may you die!” Framing the LGBT subject in online comments. Lodz Papers in Pragmatics 14(1). 69-92.

Baider, Fabienne \& Maria Constantinou. 2014. Language of cyber-politics: 'Imaging/ imagining' communities. Lodz Papers in Pragmatics 10(2). 213-244.

Baker, Paul \& Jesse Egbert (eds.). 2016. Triangulating Methodological Approaches in CorpusLinguistic Research. London: Routledge.

Banks, James. 2010. Regulating hate speech online. International Review of Law, Computers and Technology 24 (3). 233-239.

Barton, David \& Carmen Lee. 2013. Language Online: Investigating Digital Texts and Practices. Abingdon: Routledge.

Butler, Judith. 2009. Performativity, precarity and sexual politics. Revista de Antropología Iberoamericana 4(3). i-xiii.

Chakraborti, Neil, Jon Garland \& Stevie-Jade Hardy. 2014. The Leicester Hate Crime Project. Findings and Conclusions. Leicester: University of Leicester.

Citron, Keats. 2009. Cyber civil rights. Boston University Law Review 89. 61-125.

Citron, Keats \& Helen L. Norton. 2011. Intermediaries and hate speech: Fostering digital citizenship for our information age. Boston University Law Review 91(4).1435-1484.

Coleman, Gabriella. 2002. Phreaks, hackers, and trolls: The politics of transgression and spectacle. In Michael Mandiberg (ed.), The Social Media Reader, 99-119. New York and London: New York University Press.

Consalvo, Mia \& Charles Ess. 2011. The Handbook of Internet Studies. West Sussex: Wiley.

Couldry, Nick. 2012. Media, Society, World: Social Theory and Digital Media. Cambridge: Polity Press. 
Davidson, Julia \& Elena Martelozzo. 2013. Exploring young people's use of social networking sites and digital media in the internet safety context: A comparison of the UK and Bahrain. Information, Communication \& Society 16. 1-21.

Dutton, William H. (ed.). 2013. The Oxford Handbook of Internet Studies. Oxford: Oxford University Press.

Epley, Nicholas \& Justin Kruger. 2005. When what you type isn't what they read: The perseverance of stereotypes and expectancies over e-mail. Journal of Experimental Social Psychology 41(4). 414-422.

Fairclough, Norman. 1995. Critical Discourse Analysis: Papers in the Critical Study of Language. London: Longman.

Fairclough, Norman. 2003. Analyzing Discourse: Textual Analysis for Social Research. London: Routledge.

Fairclough, Norman \& Ruth Wodak. 1997. Critical Discourse Analysis. In Teun van Dijk (ed.), Discourse Studies. A Multidisciplinary Introduction - Vol. 2. Discourse as Social Interaction, 258-84. London: SAGE.

Fichman, Pnina \& Madelyn Sanfilippo. 2016. Online Trolling and Its Perpetrators: Under the Cyberbridge. Lanham: Rowman and Littlefield.

Foucault, Michel. 1971. Nietzsche, la genealogie, l'histoire. In Suzanne Bachelard, Georges Canguilhem, François Dagognet (eds.), Hommage à Jean Hyppolite, 145-72. Paris: Presses Universitaire de France.

Granovetter, Mark. 1973. The strength of weak ties. American Journal of Sociology 78(6).1360-1380.

Guadagno, Rosanna \& Robert Cialdini. 2002. Online persuasion: An examination of gender differences in computer-mediated interpersonal influence. Group Dynamics: Theory, Research, and Practice 6(1). 38-51.

Hardaker, Claire. 2013. What is turning so many young men into trolls? The Guardian. Retrieved from: http://www.theguardian.com/media/2013/aug/03/ how-to-stop-trolls-social-media_accessed 12/4/2018).

Henry, Nicola \& Anastasia Powell. 2018. Technology-facilitated sexual violence: a literature review of empirical research. Trauma, Violence, \& Abuse 19 (2). 195-208.

Herring, Susan. 2001 Computer-Mediated Discourse. In Deborah Tannen, Deborah Schiffrin \& Heidi Hamilton (eds.), Handbook of Discourse Analysis, 612-634. Oxford: Blackwell.

Herring, Susan. 2004. Computer-Mediated Discourse Analysis: An Approach to Researching Online Behavior. In Sasha A. Barab, Rob Kling \& James H. Gray (eds.), Designing for Virtual Communities in the Service of Learning, 339-376. New York: Cambridge University Press.

Herring, Susan, Kirk Job-Sluder, Rebecca Scheckler \& Sasha Barab. 2002. Searching for safety online: Managing "trolling" in a feminist forum. Information Society 18(5). 371-384.

Hine, Christine. 2000. Virtual Ethnography. London: Sage.

Hunsinger, Jeremy, Lisbeth Klastrup \& Matthew M. Allen (eds.). 2010. International Handbook of Internet Research. London, New York: Springer.

Jane, Emma A. 2014. "Your a ugly, whorish, slut" - understanding e-bile. Feminist Media Studies 14(4). 531-546.

Jane, Emma A. 2015. Flaming? What flaming? The pitfalls and potentials of researching online hostility. Ethics and Information Technology 17(1). 65-87.

Jane, Emma A. 2016. Online misogyny and feminist digilantism, Continuum 30(3). 284-297, Jane, Emma A. 2017. Misogyny Online: A Short (and Brutish) History. London: Sage. 
Joinson, Adam. 2003. Understanding the Psychology of Internet Behaviour: Virtual Worlds, Real Lives. New York: Palgrave Macmillan.

Kaufer, David. 2000. Flaming: A White Paper. Pittsburgh, PA: Department of English, Carnegie Mellon University.

Keipi, Teo, Matti Näsi, Atte Oksanen \& Pekka Räsänen. 2017. Online Hate and Harmful Content: Cross-National Perspectives. London: Routledge.

KhosraviNik, Majid. 2010. Actor descriptions, action attributions, and argumentation: towards a systematization of CDA analytical categories in the representation of social groups. Critical Discourse Studies 7(1).55-72.

KhosraviNik, Majid. 2014. Critical discourse analysis, power and new media discourse. In Yusuf Kalyango \& Monika Kopytowska (eds.), Why Discourse Matters: Negotiating Identity in the Mediatized World, 287-306. New York: Peter Lang.

KhosraviNik, Majid. 2015a. Discourse, Identity and Legitimacy: Self and Other Representation in Discourses on Iran's Nuclear Programme. Amsterdam: John Benjamins.

KhosraviNik, Majid. 2015b. Macro and micro legitimation in discourse on Iran's nuclear programme: The case of Iranian national newspaper Kayhan. Discourse \& Society 21(1). 52-73.

KhosraviNik, Majid. 2017a. Social Media Critical Discourse Studies (SM-CDS). In John Flowerdew \& John E. Richardson (eds.), Handbook of Critical Discourse Analysis, 583-596. London: Routledge.

KhosraviNik, Majid. 2017b. Right wing populism in the West: Social Media Discourse and Echo Chambers. Insight Turkey 19(3). 53-68.

KhosraviNik, Majid. 2018. Social Media Techno-Discursive Design, Affective Communication and Contemporary Politics. Fundan Journal of the Humanities and Social Sciences 2018 (ePub ahead of Print), 1-16.

KhosraviNik, Majid \& Darren Kelsey. Forthcoming. Social Media, Discourse and Politics. London: Bloomsbury.

KhosraviNik, Majid \& Mahrou Zia. 2014. Persian nationalism, identity and anti-Arab sentiments in Iranian Facebook discourses: Critical discourse analysis and social media communication. Journal of Language and Politics 13(4). 755-780

KhosraviNik, Majid \& Johann Unger 2016. Critical discourse studies and social media: Power, resistance and critique in changing media ecologies. In Ruth Wodak and Michael Meyer (eds.), Methods of Critical Discourse Analysis, $3^{\text {rd }}$ edn, 205-234. London: Sage.

KhosraviNik, Majid \& Nadia Sarkhoh. 2017. Arabism and anti-Persian sentiments on participatory web: A social media critical discourse study (SM-CDS). International Journal of Communication 11.3614-3633.

Kiesler, Sara, Jane Siegel \& Timothy W. McGuire. 1984. Social psychological aspects of computermediated communication. American Psychologist 39(10). 1123-1134.

Kopytowska, Monika. 2013. Blogging as the mediatization of politics and a new form of social interaction - a case study of Polish and British political blogs. In Piotr Cap \& Urszula Okulska (eds.) Analyzing Genres in Political Communication, 379-421. Amsterdam: John Benjamins.

Kopytowska, Monika. 2015. Mediating identity, ideology and values in the public sphere: towards a new model of (constructed) social reality. Lodz Papers in Pragmatics 11(2). 133-156.

Kopytowska, Monika. 2017. Introduction: Discourses of Hate and Radicalism in Action. In Monika Kopytowska (ed.), Contemporary Discourses of Hate and Radicalism across Space and Genres, 1-12. Amsterdam: John Benjamins. 
Kopytowska, Monika \& Fabienne Baider. 2017. From stereotypes and prejudice to verbal and physical violence: Hate speech in context. Lodz Papers in Pragmatics. 13(2). 133-152.

Kopytowska, Monika, Łukasz Grabowski \& Julita Woźniak. 2017. Mobilizing against the Other: cyberhate, refugee crisis and proximization. In Monika Kopytowska (ed.), Contemporary Discourses of Hate and Radicalism across Space and Genres, 57-98. Amsterdam: John Benjamins.

Kopytowska Monika \& Paul Chilton. 2018. "Rivers of Blood": Migration, fear and threat construction. Lodz Papers in Pragmatics 14(1). 133-161.

Kress, Gunther \& Theo van Leeuwen. (2006) [1996]. Reading Images: The Grammar of Visual Design ( $2^{\text {nd }}$ edn.). New York: Routledge.

Lange, Patricia 2006. What is your claim to flame? First Monday 11(9). Retrieved from: http://firstmonday.org/ojs/index.php/fm/article/view/1393 (accessed 2/4/2018).

Langton, Rae. 1993. Speech acts and unspeakable acts. Philosophy \& Public Affairs 22(4). 293-330.

Langton, Rae. 2012. Beyond Belief: Pragmatics in Hate Speech and Pornography. In Ishani Maitra \& Mary Kate McGowan (eds.), Speech \& Harm. Controversies over Free Speech, 72-93. Oxford: Oxford University Press.

Lazar, Michelle. 2007. Feminist Critical Discourse Analysis: Articulating a Feminist Discourse Praxis. Critical Discourse Studies 4(2). 141-164.

Lea, Martin, Tim O’Shea, Pat Fung \& Russell Spears. 1992. Flaming in computer-mediated communication-Observations, explanations, implications. In Martin Lea (ed.), Contexts of computer mediated communication, 89-112. New York: Harvester-Wheatsheaf.

Lewandowska-Tomaszczyk, Barbara. 2017. Incivility and confrontation in online conflict discourses. Lodz Papers in Pragmatics 13(2) 347-367.

Lillian, Donna. 2007. A thorn by any other name: Sexist discourse as hate speech. Discourse \& Society 18(6). 719-740.

Machin, David \& Andrea Mayr. 2012. How to Do Critical Discourse Analysis: A Multimodal Introduction. London: Sage.

Marwick, Alice E. \& Danah Boyd. 2014. Networked privacy: How teenagers negotiate context in social media. New Media \& Society 16(7). 1051-1067.

McKenna, Katelyn Y.A. \& John A. Bargh. 2000. Plan 9 from Cyberspace: The Implications of the Internet for Personality and Social Psychology. Personality and Social Psychology Review 4. 57 75.

Moor, Peter, Ard Heuvelman \& Ria Verleur. 2010. Flaming on YouTube. Computers in Human Behavior 26. 1536-1546.

O’Sullivan, Patrick \& Andrew J. Flanagin. 2003. Reconceptualizing 'flaming' and other problematic messages. New Media and Society 5(1). 69-94.

Organization for Security and Cooperation in Europe (OSCE) / Office for Democratic Institutions and Human Rights (ODIHR). 2009. Hate crime laws: A practical guide. Retrieved from: http://www.osce.org/odihr/36426 (accessed 12/4/2018).

Page, Ruth, David Barton, Johann W. Unger, \& Michele Zappavigna. 2014. Researching Language and Social Media: A Student Guide. London: Routledge.

Phillips, Whitney. 2011. LOLing at tragedy: Facebook trolls, memorial pages and resistance to grief online. First Monday 16(12). Retrieved from: http://firstMonday.org/ojs/index.php/fm/article/view/3168 (accessed 12/4/2018).

Phillips, Whitney. 2012. The house that fox built: Anonymous, spectacle, and cycles of amplification. Television and New Media 14(6). 494-509. 
Postmes, Tom, Russell Spears \& Martin Lea. 2002. Intergroup differentiation in computer-mediated communication: Effects of depersonalization. Group Dynamics 6(1). 3-16.

Powell, Anastasia and Nicola Henry. 2017. Sexual Violence in a Digital Age. Palgrave Macmillan.

Ragnedda, Massimo \& Glenn Muschert (eds.) 2013. The Digital Divide: The Internet and Social Inequality in International Perspective. London: Routledge.

Reisigl, Martin. 2014. Argumentation analysis and the Discourse-Historical Approach. A Methodological Framework. In Christopher Hart \& Piotr Cap (eds.), Contemporary Critical Discourse Studies, 67-96. London: Bloomsbury.

Reisigl, Martin \& Ruth Wodak. 2001. Discourse and Discrimination: Rhetoric of Racism and AntiSemitism. London: Routledge.

Reisigl, Martin \& Ruth Wodak. 2009. The Discourse-Historical Approach. In Ruth Wodak and Michael Meyer (eds.), Methods of Critical Discourse Analysis, $2^{\text {nd }}$ edn, 87-121. London: Sage.

Sarkeesiaan, Anita. 2015. "Stop the Trolls. Women Fight Back Online Harassment". Women in the World. Retrieved from: https://www.youtube.com/watch?v= BGrlk8_kevI (accessed 12/4/2018).

Siegel, Jane, Vitaly Dubrovsky, Sara Kiesler \& Timothy W. McGuire. 1986. Group processes in computer-mediated communication. Organizational Behavior and Human Decision Processes 37(2). 157-187.

Suler, John \& Wende Phillips. 1998. The Bad Boys of Cyberspace: Deviant Behavior in a Multimedia Chat Community. CyberPsychology \& Behavior 1(3). 275-294.

Thurlow, Crispin, Laura Lengel \& Alice Tomic. 2009. Computer Mediated Communication: Social Interaction and the Internet. London: Sage.

Titley, Gavan. 2012. Hate Speech Online: Considerations for the Proposed Campaign. Starting Points for Combating Hate Speech Online. Strasbourg: Council of Europe. Retrieved from: https://rm.coe.int/1680665ba7 (accessed 12/4/2018.

Turnage, Anna. 2007. Email flaming behaviors and organizational conflict. Journal of ComputerMediated Communication 13.43-59.

Waldron, Jeremy. 2012. The Harm in Hate Speech. Cambridge: Harvard University Press.

Wallace, Patricia. 2016. The Psychology of the Internet. New York: Cambridge University Press.

Weber, Anne. 2009. Manual on hate speech, Council of Europe Publishing. Retrieved from: https://www.coe.int/t/dghl/standardsetting/hrpolicy/

Publications/Hate_Speech_EN.pdf (accessed 12/4/2018).

Weisband, Suzanne \& Leanne Atwater. 1999. Evaluating Self and Others in Electronic and Face- toFace Groups. Journal of Applied Psychology 84. 632- 639.

Whillock, Rita Kirk. 1995. The use of hate as a stratagem for achieving political and social goals. In Rita Kirk Whillock \& David Slayden (eds.), Hate Speech, 28-54. London: Sage.

Wodak, Ruth \& Michael Meyer. 2016. Methods of Critical Discourse Analysis, $3^{\text {rd }}$ edn. London: Sage. 


\begin{abstract}
About the Authors
Majid KhosraviNik is Senior Lecturer in Digital Media \& Discourse Studies at Newcastle University. He teaches modules on Digital Discourses \& Identity and Politics, Power \& Communication at the School of Arts \& Cultures while supervising a number of doctoral and post-doctoral projects. He has published widely on critical discourse studies including immigration discourses, self and other representation, national identity, right wing populism, and regional identities in the Middle East. He is specifically interested in digital media discursive practices. Majid researches the intersection of participatory web, discourse and politics by investigating the impact, dynamic and challenges of social media technologies within a Social Media Critical Discourse Studies (SM-CDS) model. Majid is a founder of Newcastle Critical Discourse Studies, sits on editorial board of Critical Discourse Studies (Routledge) and Journal of Language \& Politics (John Benjamins) while acting as an expert evaluator and moderator for a range of leading international publishers and research grant organizations including the EU commission.
\end{abstract}

\title{
Address
}

Media, Culture, Heritage, School of Arts and Cultures

Armstrong Building

University of Newcastle

Newcastle upon Tyne, NE1 7RU

UK

e-mail: majid.khosravinik@newcastle.ac.uk

Eleonora Esposito is Marie Skłodowska-Curie Research Fellow at the University of Navarra (Spain). She holds a M.A. in Cultural and Postcolonial Studies (University of Naples L'Orientale, 2010) and a PhD / Doctor Europaeus in English Linguistics (University of Naples Federico II, 2015). Her research interests are in the field of Language, Politics, Gender and Society in the European Union and in the Anglophone Caribbean, investigated in the light of Critical Discourse Studies, Multimodal Studies and Translation Studies. Currently, Eleonora is exploring new theoretical perspectives and integrated methodologies for the critical investigation of Social Media Discourses, with a focus on online hostility and misogyny.

\author{
Address \\ Institute for Culture and Society (ICS) \\ University of Navarra \\ Calle Universidad 6 \\ 31009 Pamplona \\ Spain \\ e-mail: eleonora.esposito84@gmail.com
}

